\title{
The effects of transcranial electrical stimulation on opiate-induced analgesia in rats
}

\author{
Ayla A Kabalak MD ${ }^{1}$, Oytun O Senel DVM ${ }^{2}$, Nermin Gogus MD ${ }^{1}$
}

\begin{abstract}
AA Kabalak, OO Senel, N Gogus. The effects of transcranial electrical stimulation on opiate-induced analgesia in rats. Pain Res Manage 2004;9(4):203-206.
\end{abstract}

BACKGROUND AND OBJECTIVES: Recent experiments have shown that transcranial electrical stimulation significantly increases the potency and duration of the analgesic effects of opioids in humans and rats. In the present study, the influence of transcranial electrical stimulation (TCES) on the analgesic effect of remifentanil hydrochloride $(\mathrm{HCl})$ in rats was determined.

METHODS: Experiments were performed on 80 albino male Wistar rats. Rats were randomly assigned to four groups: remifentanil $\mathrm{HCl}$, remifentanil $\mathrm{HCl}$ and TCES, TCES, and control ( $n=20 /$ group). Remifentanil $\mathrm{HCl}$ was injected on the 55th minute. Analgesia was assessed using the wet tail-flick latency test.

RESULTS: In the remifentanil $\mathrm{HCl}$ group, analgesia $(10.85 \pm 1.04 \mathrm{~s})$ was reached at the fifth minute, and the analgesia was high for the first $10 \mathrm{~min}$. In the remifentanil $\mathrm{HCl}$ and TCES group, the latency time peaked $(16.60 \pm 1.19 \mathrm{~s})$ at the fifth minute. This peak was $150 \%$ higher than that for the remifentanil $\mathrm{HCl}$ group, and 251\% higher than the control or TCES groups. Analgesia in the remifentanil $\mathrm{HCl}$ and TCES group was sustained for $20 \mathrm{~min}$ at a statistically higher rate than the other treatment groups $(\mathrm{P}<0.001)$.

CONCLUSIONS: TCES markedly increased the duration and analgesic potency of remifentanil $\mathrm{HCl}$ in rats. This effect appeared to be related to the release of enkephalins from brain structures, thus enhancing opioid analgesia.

Key Words: Analgesia; Remifentanil; Transcranial electrical stimulation

\section{Les effets de l'électrostimulation crânienne sur une analgésie aux opiacés chez des rats}

HISTORIQUE ET OBJECTIFS : Des expériences récentes démontrent que la stimulation électrique transcrânienne augmente considérablement la puissance et la durée des effets analgésiques des opiacés chez les humains et les rats. Dans la présente étude, l'influence d'une électrostimulation crânienne (ESC) sur l'effet analgésique de l'hydrochlorure de rémifentanil (HCR) chez les rats a été déterminée.

MÉTHODOLOGIE : Des expériences ont été exécutées sur 80 rats Wistar mâles albinos. Les rats ont été divisés aléatoirement en quatre groupes : HCR, HCR et ESC, ESC et groupe témoin ( $n=20$ par groupe). L'HCR a été injecté à la $55^{\mathrm{e}}$ minute. L'analgésie a été évaluée au moyen du test de latence de rétraction de la queue.

RÉSULTATS : Dans le groupe HCR, l'analgésie $(10,85 \pm 1,04$ s) a été obtenue à la $5^{\mathrm{e}}$ minute et a été élevée pendant les 10 premières minutes. Dans le groupe HCR et ESC, la période de latence a atteint un sommet $(16,60 \pm 1,19 \mathrm{~s})$ la $5^{\mathrm{e}}$ minute. Ce sommet était $150 \%$ plus élevé que dans le groupe HCR, et $251 \%$ plus élevé que dans les groupes témoin et ESC. L'analgésie dans le groupe HCR et ESC a été maintenue 20 minutes à un taux statistiquement plus élevé que dans les autres groupes de traitement $(\mathrm{P}<0,001)$.

CONCLUSIONS : L'ESC augmentait de manière considérable la durée et la puissance analgésique du HCR chez les rats. Cet effet semblait relié à la libération d'enképhalines dans les structures cérébrales, qui accroissait l'analgésie aux opiacés.
$\mathrm{H}$ istorically, electrical pulses have been used for pain inhibition in animals. Different models and new techniques of electrical stimulation have been employed in both animals and humans using 'transcranial electrical stimulation (TCES)', which involves low-frequency electrical currents. However, low-frequency electrical currents have always been associated with severe side effects such as apnea, cardiac accidents and convulsions $(1,2)$; therefore, different stimulation methods were developed. High-frequency TCES consists of lowfrequency trains of high-frequency current. This method allows for an increase in current intensity without the reduction of tissue conductivity that is normally associated with low-frequency currents. This type of TCES is called 'Limoge's current' $(3)$. Recent experiments $(3,4)$ have shown that TCES significantly increases the analgesic effects of morphine and dexamethasone in humans and rats. Undesirable side effects attributable to TCES have not been reported in these studies. The preliminary results obtained from TCES in the field of clinical anesthesia seem to be promising. A better quality of anesthesia, a faster recovery from anesthesia, and a long-lasting postoperative analgesic period can be obtained in especially high-risk patients by decreasing analgesic requirements (2-6).

In the present study, we used remifentanil hydrochloride $(\mathrm{HCl})$, which is used in acute pain relief, to test the effects of opioids because it had not been previously studied with respect to TCES. In addition, remifentanil $\mathrm{HCl}$ is a new, ultrashortacting mu-opioid agonist that is metabolized by plasma and tissue esterases. The elimination half-life of remifentanil $\mathrm{HCl}$ is

${ }^{1}$ Department of Anaesthesiology and Reanimation, Ankara Numune Research and Training Hospital; ${ }^{2}$ Department of Surgery, Faculty of Veterinary Medicine, Ankara University, Ankara, Turkey

Correspondence: Dr Ayla A Kabalak, Cigdem Mah, 337 sok, Tugba apartment, 5/2, Balgat, 06530, Ankara, Turkey.

Telephone 90-312-286-12-85, fax 90-312-286-12-85, e-mail drayla2002@yahoo.com 


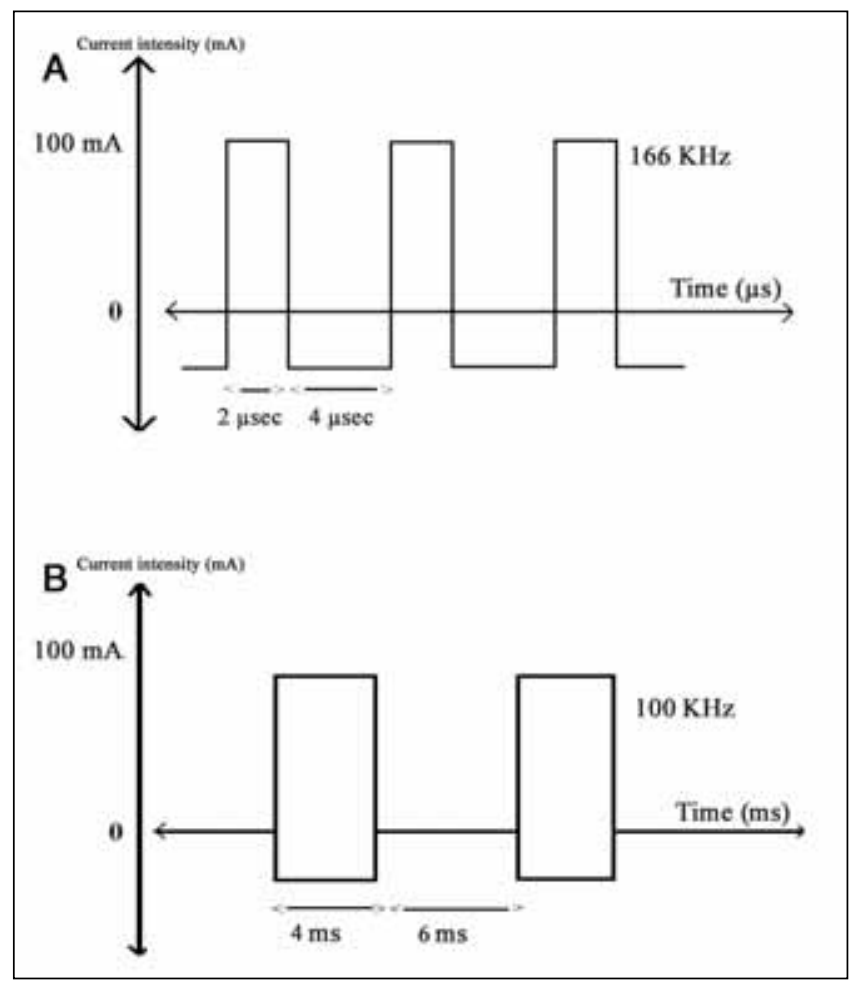

Figure 1) Characteristics of transcranial electrical stimulation with Limoge's current. (A) High frequency $166 \mathrm{kHz}, 2 \mu \mathrm{s}+, 4 \mu \mathrm{s}-$ and (B) intermittent low frequency $100 \mathrm{KHz}, 4 \mathrm{~ms}$

approximately $10 \mathrm{~min}$ to $20 \mathrm{~min}$ (7). Intraperitoneal remifentanil $\mathrm{HCl}$ reaches its peak effect in $5 \mathrm{~min}$, and its duration of action is approximately $10 \pm 5 \mathrm{~min}$ in rats (8).

The aim of the present study was to determine the influence of TCES with Limoge's current on the analgesic effect and duration of short-acting remifentanil $\mathrm{HCl}$ in rats.

\section{METHODS}

\section{Animals}

The present study was approved by the Committee for Research and Ethical Issues of Ankara University's Veterinary Faculty (Ankara, Turkey). Experiments were performed on 80 albino male Wistar rats (Hifzisihha Institute, Ankara, Turkey) weighing $140 \mathrm{~g}$ to $180 \mathrm{~g}$. Rats were housed on a $12 \mathrm{~h}: 12 \mathrm{~h}$ alternating light/dark cycle with food and water ad libitum. The study rats had no prior exposure to electric stimulation or analgesics. A day before each experiment, the rats were placed in a transparent pliant box for $60 \mathrm{~min}$ to acclimate them to the experimental conditions. Experiments took place between 16:00 and 20:00. Rats were randomly assigned to four study groups, each consisting of 20 rats: the remifentanil $\mathrm{HCl}$ group $(\mathrm{R})$, the remifentanil $\mathrm{HCl}$ and TCES group (R+TCES), the TCES group and the control group (C).

\section{Electrode placement}

Each rat was confined to a transparent pliant box designed to keep the rat's head and tail free and out of the box. The box was perforated for injection into the abdomen. The rat was restrained to ease the conduct of the experiment. Venous needles were used to make the electrodes. The frontal electrode was placed on the cranium between the eyes on the metopic suture, and the two posterior electrodes were placed behind the mastoid bones on each side
TABLE 1

Groups and experimental procedure

\begin{tabular}{lccc}
\hline Group $(\mathbf{n = 2 0})$ & TCES & $\begin{array}{c}\text { Remifentanil hydrochloride (R) } \\
\text { or saline treatment }\end{array}$ & TFL \\
\hline $\mathrm{R}$ & - & $1 \mu \mathrm{g} / \mathrm{kg}$ & $5 \mathrm{~min}$ intervals \\
R+TCES & Limoge's current $(5 \mathrm{~min})$ & $1 \mu \mathrm{g} / \mathrm{kg}$ & $5 \mathrm{~min}$ intervals \\
TCES & Limoge's current $(5 \mathrm{~min})$ & Isotonic saline & 5 min intervals \\
Control* & - & Isotonic saline & 5 min intervals \\
\hline
\end{tabular}

${ }^{*}$ Drug and stimulation-free. TCES Transcranial electrical stimulation; TFL Tail-flick latency

(3). Electrodes were connected to an electrical generator with thin and flexible cables.

\section{TCES}

The stimulation was provided by a home-made generator calibrated with a digital oscilloscope (Multimeter, Hewlett Packard 973 A, USA). The electrical currents (Limoge's current) consisted of lowfrequency trains of high-frequency current (high-frequency intermittent bursts of bidirectional balanced currents: $166 \mathrm{kHz}$, low frequency; $4 \mathrm{~ms}$ at $100 \mathrm{~Hz}$; current intensity: $100 \mathrm{~mA}$ ). In each high-frequency cycle, the current was positive for $2 \mu$ and negative for $4 \mu$ s (Figure 1). The frontal electrode was connected to the negative pole of the generator and received the negative impulse of weak intensity of $33 \mathrm{~mA}$ (long duration $4 \mu \mathrm{s}$ ). The two posterior electrodes were connected to the positive pole and received the positive impulse of $67 \mathrm{~mA}$ (short duration $2 \mu \mathrm{s}$ ) (3). The average intensity was zero, which completely eliminated electrode burns from electrolysis. A constant current circuit was added to maintain the same intensity whenever the electrodes interfaced impedance change. After the placement of the electrodes, the TCES and R+TCES groups were stimulated for $60 \mathrm{~min}$. The stimulation was continued in on-and-off 5 min cycles until the end of the experiment. The electrodes were placed in all groups, but the $\mathrm{R}$ and control groups were not exposed to electrical stimulation.

\section{Analgesia}

Remifentanil $\mathrm{HCl}$ was dissolved in isotonic saline and injected intraperitoneally $(1 \mu \mathrm{g} / \mathrm{kg})$ with a 25 gauge needle (total volume of $1 \mathrm{~mL}$ ) (Table 1). Groups $\mathrm{R}$ and R+TCES received remifentanil $\mathrm{HCl}$ on the 55th minute of stimulation, whereas the TCES and control groups were injected with only $1 \mathrm{~mL}$ of isotonic saline to equalize the painful stimulus effect of injection.

\section{Measurement of analgesia}

Analgesia was assessed using the wet tail-flick latency (TFL) test (9). The terminal third of the rat's tail was immersed in a thermostat water bath $\left(50^{\circ} \mathrm{C}\right)$, and the time required for initiating the retreat reflex time (seconds) was measured. For TFL measurements, the rats were disconnected from the stimulator for a short period. The time required for the retreat reflex was measured with a chronometer in the immersion TFL as previously desecribed (10). The first tail movement imposed a time count interrupt. If the tail retreat reflex did not occur after $20 \mathrm{~s}$, the tail was manually withdrawn from the water to avoid tissue damage.

The first TFL test was applied to all groups on the 60th minute of TCES, and then repeated every 5 min until the same values were measured in all groups.

To observe the effects of TCES on rat movements (head, muzzle and eye), rat reactions were monitored in the TCES group and compared with those of the control group. 


\section{Statistical analysis}

Quantitative data was compared in terms of mean and SD of TFL. One-way ANOVA was used for the comparisons between and within the groups for time-dependent differences. The Dunnett test was done for comparisons with the control group. The Tamhane test was performed when comparing the period of nonhomogeneous distribution ( $5 \mathrm{~min}$ to $15 \mathrm{~min}$ ) between groups and the Tukey HSD test on those with homogenous distribution. All tests were performed using SPSS 11.5 (SPSS Inc, USA).

\section{RESULTS}

All results were expressed as mean $\pm \mathrm{SD}$. No major adverse effects were observed throughout the procedures.

The control TFL test value was $4.75 \pm 0.72 \mathrm{~s}$ at the fifth minute. The retreat reflex time in the TCES group was similar to the control TFL test result at fifth to 30th minute after the injection (Figure 2). TCES with Limoge's current did not modify the pain threshold during stimulation in the TCES group. Analgesia was increased by remifentanil $\mathrm{HCl}$ in the $\mathrm{R}$ group. In addition, remifentanil $\mathrm{HCl}$-induced analgesia was increased by TCES.

In the $\mathrm{R}$ group, the retreat reflex time reached a peak value $(10.85 \pm 1.04 \mathrm{~s})$ at the fifth minute (60th minute of TCES), which was significantly longer than the TCES and control group values at the fifth and 10 th minute $(\mathrm{P}<0.001)$. TFL test results at the 15th minute returned to control TFL values and were similar to the TCES and control group values.

The retreat reflex time reached a peak value $(16.60 \pm 1.19 \mathrm{~s})$ at the fifth minute (60th minute of TCES) in the R+TCES group; this value was five times greater than those of the TCES and control groups. In the R+TCES group, at the fifth to 20th minute following remifentanil $\mathrm{HCl}$ injection, retreat reflex time was significantly longer than the other groups $(\mathrm{P}<0.001)$. TCES-induced analgesia with remifentanil $\mathrm{HCl}$ was observed for $20 \mathrm{~min}$; however, a progressive decrease in analgesia with time was observed, and values reached the control TFL values by the 25th minute in the R+TCES group.

The TFL value of the $\mathrm{R}$ group was $131 \%$ higher than the TFL values of the control and TCES groups at the fifth minute $(\mathrm{P}<0.001)$. In the $\mathrm{R}+\mathrm{TCES}$ group, this increase reached $251 \%$ compared with the control and TCES groups at the fifth minute $(\mathrm{P}<0.001)$. Furthermore, the analgesic potency for the $\mathrm{R}+\mathrm{TCES}$ group increased by $150 \%, 162 \%, 124 \%$ and $93 \%$ compared with the R group at the fifth, 10th, 15th and 20th minute, respectively $(\mathrm{P}<0.001)$. The results suggested that remifentanil $\mathrm{HCl}$-induced analgesia was potentiated by TCES. The analgesia in the R+TCES group decreased to control values by the 25 th minute following remifentanil $\mathrm{HCl}$ administration.

Nonquantitative observations indicated that TCES did not affect the movements of the rats in the TCES group. The rat movements were similar in the TCES and control groups.

\section{DISCUSSION}

The R+TCES group presented a statistically significant nociceptive threshold above that of the $\mathrm{R}$ group. We found a positive correlation between TCES and analgesic effects.

Mathematical analysis of Limoge's current is based on the Fourier series. The presence of these electric fields in the brain may influence the endogenous opioid system (11). This is supported by the fact that TCES has been successfully used during

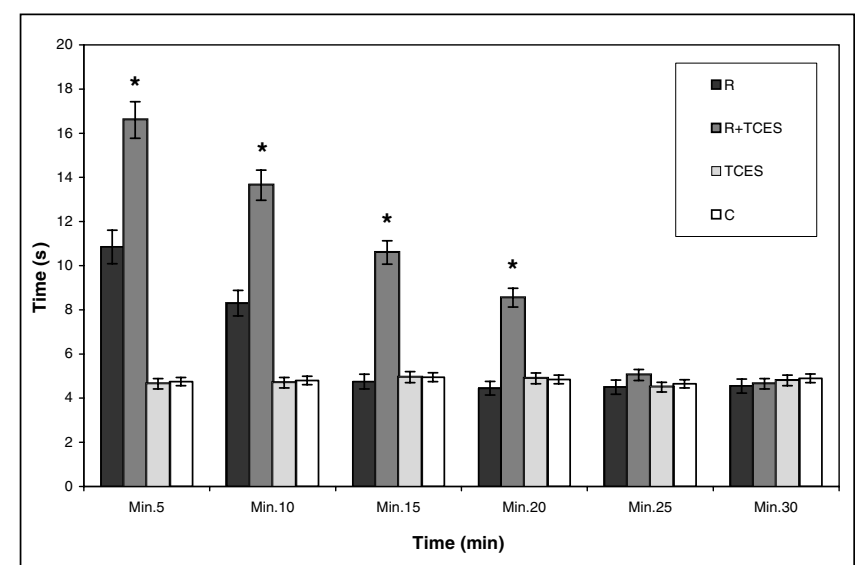

Figure 2) Effects of transcranial electrical stimulation (TCES) with Limoge's current on remifentanil hydrochloride $(R)$ analgesia in rats. Results are expressed as mean \pm SD. C Control group. *Statistically higher than the other three groups (R, TCES and C groups) $(P<0.001)$

opiate withdrawal in human heroin addicts without any adverse reactions (12). In addition, nonquantitative observations have indicated that TCES with Limoge's current does not affect the behaviour of drug-free rats $(2,3,13,14)$. In the present study, TCES did not affect the movements of the rats in the TCES group, thus allowing for the administration of stimulation without side effects.

TCES produces a naloxone-reversible analgesia in drug-free rats that is not potent $(13,14)$. This finding is supported by studies $(12,15)$ that found that opiate withdrawal syndrome faded with TCES and that this effect could be reversed with naloxone. However, other studies $(2,3)$ have shown that TCES does not modify the pain threshold in drug-free animals and humans, possibly due to the very low basal activity of central opiate systems. In our study, TCES alone did not modify the pain threshold in rats.

Stinus et al (3) observed that, in rats, morphine, fentanyl, alfentanil $\mathrm{HCl}$ and dextromoramide provided a $174 \%, 176 \%$, $160 \%$ and $267 \%$ increase in TFL, respectively, compared with control values; these increases reached 306\%, 336\%, 215\% and $392 \%$, respectively, with the addition of TCES. In the present study, analgesia increased $131 \%$ in the $\mathrm{R}$ group compared with control TFL test results at the fifth minute. This increase reached $251 \%$ in the R+TCES group at the fifth minute with the addition of stimulation.

There are different perspectives concerning the starting time of stimulation to increase analgesic effects. The beginning of analgesia, the time required for maximal effect and the end of analgesia can differ due to the current used, the location of the stimulation, the technique used to measure analgesia and the duration of the stimulation. Stinus et al (3) reported that the analgesic effects of subcutaneous morphine were increased by starting TCES $3 \mathrm{~h}$ before injection. Different observers have successfully reached analgesia using TCES for less time. Analgesia has been shown to start on the 20th minute of low-frequency stimulation $(10 \mathrm{~Hz})$ in rats (13-16). In our study, we used TCES with high frequency and began the stimulation 55 min before drug administration. Analgesia with 
TCES was high at the 60th minute (at the fifth minute of remifentanil $\mathrm{HCl}$ injection) and it remained high for $20 \mathrm{~min}$ in the R+TCES group. The analgesia lasted approximately two times longer when TCES was added to remifentanil $\mathrm{HCl}$ (compared with remifentanil $\mathrm{HCl}$ alone).

The mechanisms and neurobiological substrates of TCES remain unknown. TCES may alter the kinetics of the drug and change blood-brain barrier permeability, increasing the penetration of the drug into the brain. Perhaps it creates a new steady state in brain activity, which could be revealed by a pharmacological challenge. This phenomenon is likely centrally mediated and occurs via the enhancement of analgesia elicited by the release of endogenous opioids such as enkephalins and endorphins (1-6,16,17). Stimulation of the periaqueductal gray matter induces highly specific naloxonereversible pain suppression that is associated with increased immunoreactivity for beta endorphins in ventricular fluid $(18,19)$. Enkephalinase inhibitors increase the analgesia caused by TCES. Opioid antagonists, such as naloxone, reverse this effect. It is believed that the endogenous opioids participate in this mechanism $(2,3,12,15,17)$. On the other hand, TCES appears to cause an increase in the synthesis or release of serotonin, dopamine and noradrenaline in the midbrain, and dopamine and serotonin in the hypothalamus (20). Moreover, noradrenergic fibres (21), serotonergic fibres $(22,23)$ or both $(24)$ have been shown to play a key role in the medication of analgesics at the spinal level.

\section{CONCLUSION}

TCES markedly increases the duration and analgesic potency for remifentanil $\mathrm{HCl}$ in rats without affecting movements. This effect appears to be related to the release of enkephalins from brain structures, enhancing opioid analgesia.

ACKNOWLEDGEMENTS: The authors thank Bahattin Koç, Professor of Veterinary Surgery and Anaesthesiology (Faculty of Veterinary Medicine, Ankara University, Ankara, Turkey) for advice and help.

\section{REFERENCES}

1. Smith RH. Electroanesthesia. Anesthesiology 1971;34:60-72.

2. Hamilton RF, Collard CD, Hymel C, Wilson O, Skolnick M. Optimization of low current transcranial electrostimulation (TCES) in the production of naloxone-reversible analgesia in male rats. FASEB J 1988;2:A1071.

3. Stinus L, Auriacombe M, Tignol J, Limoge A, Le Moal M. Transcranial electrical stimulation with high frequency intermittent current (Limoge's) potentiates opiate-induced analgesia: Blind studies. Pain 1990;42:351-63.

4. Bourdallé-Badie C, Gardien P, Laforge E, Gadrat F, Erny P. [Long-lasting anaesthesia. Advantages of electroanaesthesia (author's transl)]. Anesth Analg (Paris) 1980;37:523-6.

5. Stanley TH, Cazalaa JA, Limoge A, Louville Y. Transcutaneous cranial electrical stimulation increases the potency of nitrous oxide in humans. Anesthesiology 1982;57:293-7.
6. Stanley TH, Cazalaa JA, Atinault A, Coeytaux R, Limoge A, Louville Y. Transcutaneous cranial electrical stimulation decreases narcotic requirements during neurolept anesthesia and operation in man. Anesth Analg 1982;61:863-6.

7. Westmoreland CL, Hoke JF, Sebel PS, Hug CC Jr, Muir KT. Pharmacokinetics of remifentanil (GI87084B) and its major metabolite (GI90291) in patients undergoing elective inpatient surgery. Anesthesiology 1993;79:893-903.

8. Buerkle H, Yaksh TL. Comparison of the spinal actions of the mu-opioid remifentanil with alfentanil and morphine in the rat. Anesthesiology 1996;84:94-102.

9. Yoburn BC, Morales R, Kelly DD, Inturrisi CE. Constraints on the tailflick assay: Morphine analgesia and tolerance are dependent upon locus of tail stimulation. Life Sci 1984;34:1755-62.

10. Sewell RD, Spencer PS. Antinociceptive activitiy of narcotic agonist and partial agonist analgesics and other agents in the tail-immersion test in mice and rats. Neuropharmacology 1976;15:683-8.

11. Barritault L, Orlowski S, Prieur G, Limoge A. Interprétation ionique de l'électrostimulation cérébrale transcutanée par les courants Limoge. J Med Nucl Biophys 1989;13:315-21.

12. Ellison F, Ellison W, Daulouéde JP, et al. Opiate withdrawal and electrostimulation: Double-blind experiments. Encéphale 1987;13:225-9.

13. Wilson OB, Hamilton RF, Warner RL, et al. The influence of electrical variables on analgesia produced by low current transcranial electrostimulation of rats. Anesth Analg 1989;68:673-81.

14. Skolnick MH, Wilson OB, Hamilton RF, et al. Low current electrostimulation produces naloxone-reversible analgesia rats. Stereotact Funct Neurosurg 1989;53:125-40.

15. Malin DH, Murray JB, Crucian GP, Schweitzer FC, Cook RE, Skolnick MH. Auricular microelectrostimulation: Naloxone-reversible attenuation of opiate abstinence syndrome. Biol Psychiatry 1988;24:886-90.

16. Malin DH, Lake JR, Hamilton RF, Skolnick MH. Augmented analgesia effects of enkephalinase inhibitors combined with transcranial electrostimulation. Life Sci 1989;44:1371-6.

17. Hughes J, Kosterlitz HW. Opioid peptides: Introduction. Br Med Bull 1983;39:1-3.

18. Hosobuchi Y, Adams JE, Linchitz R. Pain relief by electrical stimulation of the central gray matter in humans and its reversal by naloxone. Science 1977;197:183-6.

19. Hosobuchi Y, Rossier J, Bloom FE, Guillemin R. Stimulation of human periaqueductal gray for pain relief increases immunoreactive beta-endorphin in ventricular fluid. Science 1979;203:279-81.

20. Zhong FX, Ji XQ, Tsou K. Intrathecal DSP4 selectively depletes spinal noradrenaline and attenuates morphine analgesia. Eur J Pharmacol 1985;116:327-30.

21. Oliveras JL, Guilbaud G, Besson JM. A map of serotoninergic structures involved in producing analgesia in unrestrained freely moving cats. Brain Res 1979;164:317-22.

22. Warner R, Hudson-Howard L, Johnston C, Skolnick M. Serotonin involvement in analgesia induced by transcranial electrostimulation. Life Sci 1990;46:1131-8.

23. Hammond DL, Yaksh TL. Antagonism of stimulation-produced antinociception by intrathecal administration of methysergide or phentolamine. Brain Res 1984;298:329-37.

24. Warner RL, Johnston C, Hamilton R, Skolnick MH, Wilson OB. Transcranial electrostimulation effects on rat opioid and neurotransmitter levels. Life Sci 1994;54:481-90. 


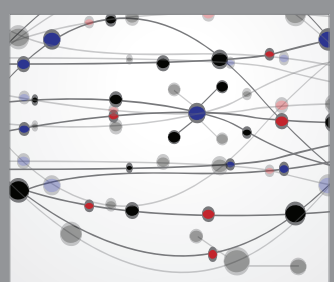

The Scientific World Journal
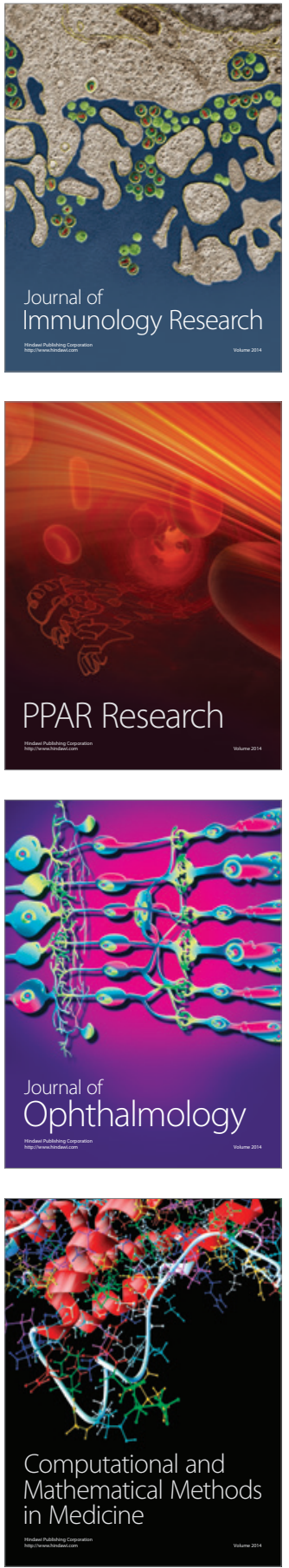

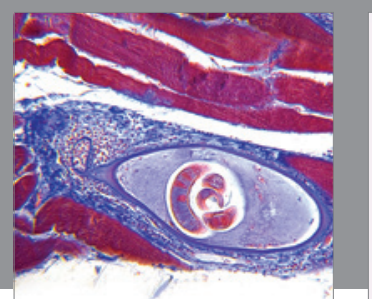

Gastroenterology Research and Practice

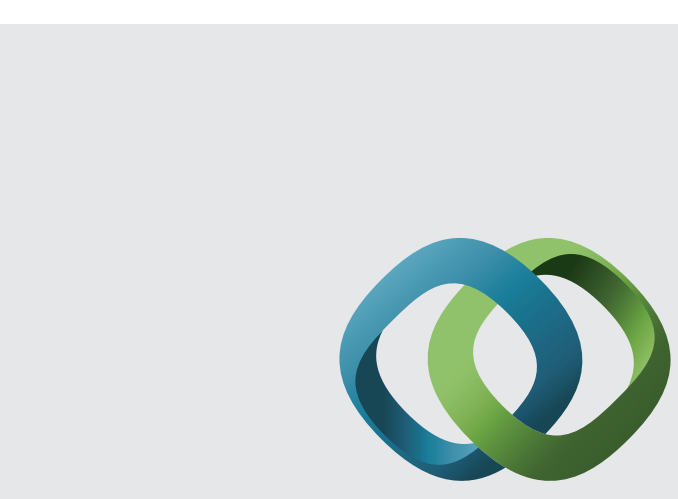

\section{Hindawi}

Submit your manuscripts at

http://www.hindawi.com
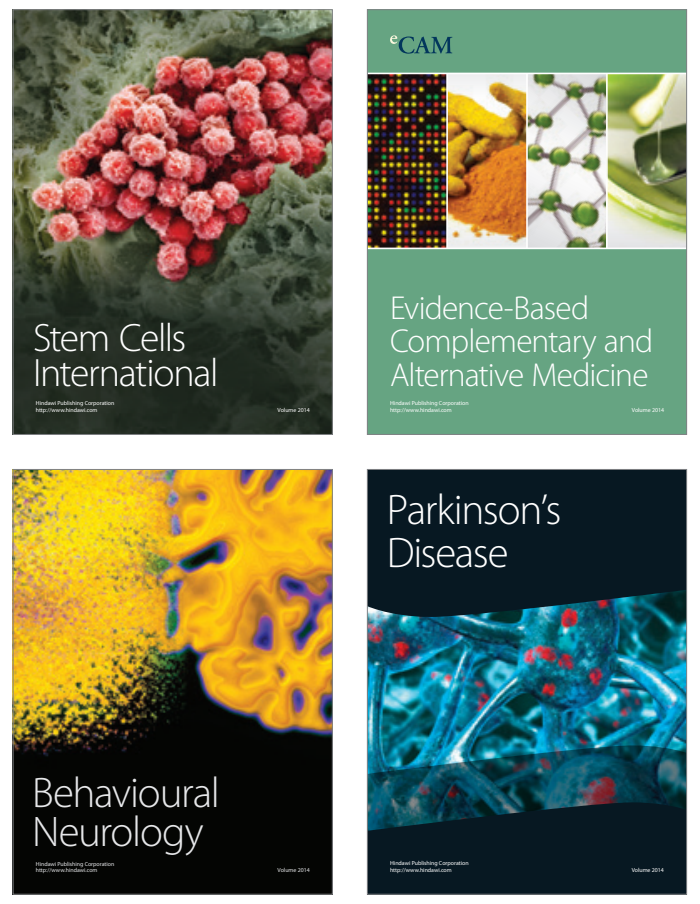
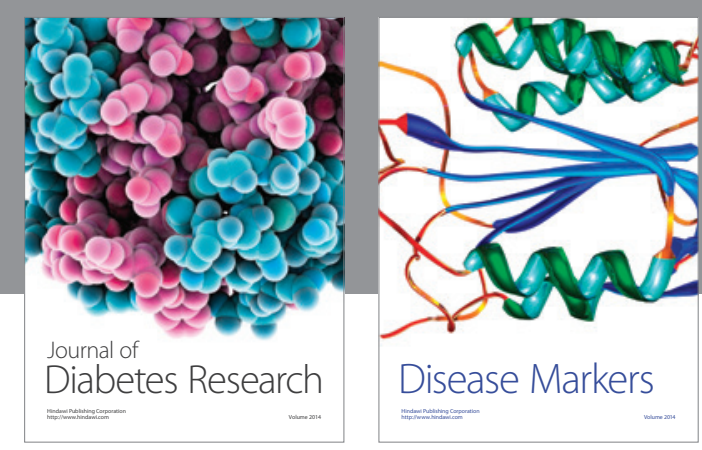

Disease Markers
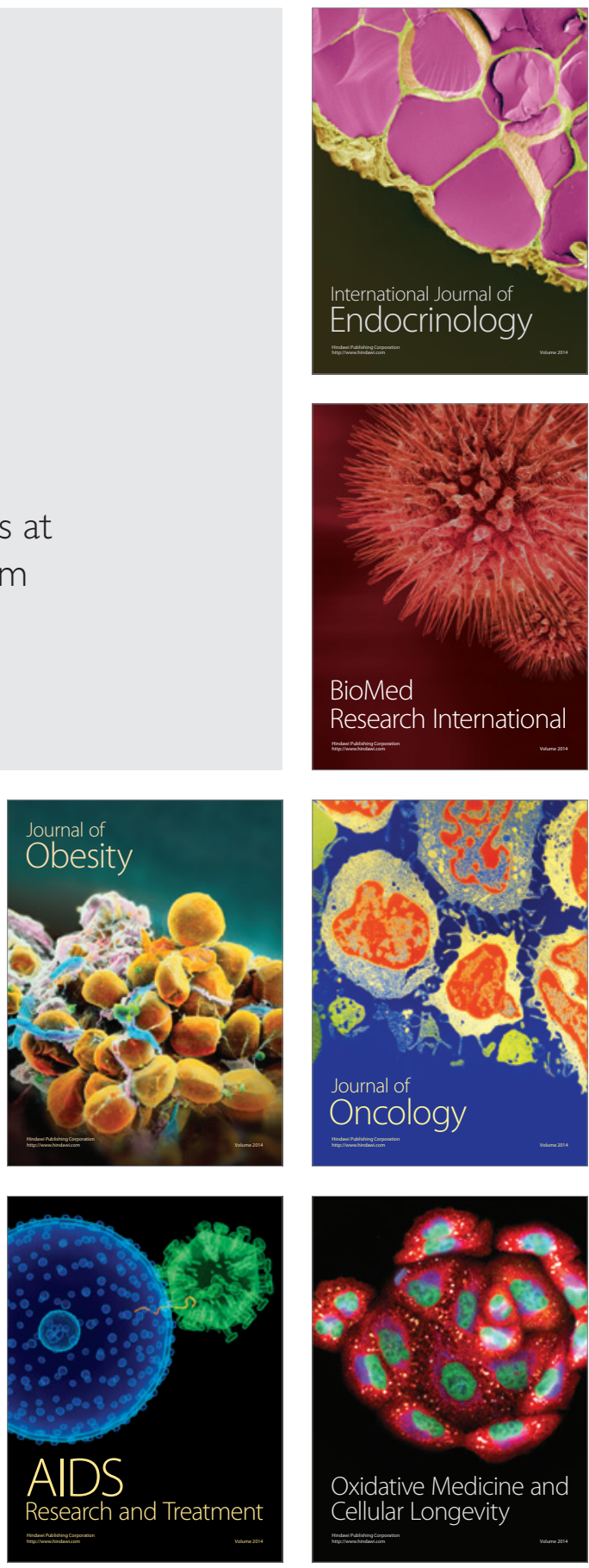